\title{
IMPACT OF COVID-19 ON USE OF NON-RENEWABLE NATURAL RESOURCES
}

\author{
Dejan Bogdanović ${ }^{1}$, Slavica Miletić ${ }^{2}$
}

Received: September 29, 2021

Accepted: November 08, 2021

\begin{abstract}
The paper analyzes the impact of the COVID-19 pandemic on the exploitation and use of non-renewable natural resources. The analysis covers the most important challenges facing this industry. The paper identifies the most important impacts of COVID-19 as well as their consequences in order to rank them. The goal of ranking is to help managers in this industry to overcome the given problems in the best way. The ranking was performed by AHP method, and the paper considers all types of non-renewable natural resources globally.
\end{abstract}

Keywords: Non-Renewable Natural Resources, COVID-19, AHP, Management

\section{INTRODUCTION}

Non-renewable natural resources are necessary for the functioning of the economy, as well as the entire chain of their users, but on the other hand, this industry is also affected by the Covid-19 pandemic.

The COVID-19 pandemic, in addition to affecting public health, has caused major economic, social and political disruptions around the world. Consequently, the pandemic has disrupted political, economic, financial and social structures around the world. It also significantly limited communication, trade, but also the availability of all goods and stopped tourism and the services sector (Delloite, 2020, Laing, 2020, Hilson et al., 2021). This has led to a decline in demand and sales of many products, so that many economic activities have slowed or stalled, including mining and the non-renewable natural resources sector (Galas et al., 2021).

Many authors who have researched the impact of the consequences of the COVID-19 pandemic on the business of companies dealing with non-renewable natural resources point to the fact that most countries have demanded the smooth continuation of the work of these companies. However, this is contrary to the apparent reduction in global demand

\footnotetext{
${ }^{1}$ University of Belgrade - Technical Faculty in Bor, Bor, Serbia

${ }^{2}$ Mining and Metallurgy Institute Bor, MMI, Bor, Serbia 
for these resources as a result of the crisis caused by the pandemic COVID-19. All this has led to excess supply so that there was a significant fall in the prices of metals (except gold) and an increase in stocks at the global level (Laing, 2020). This situation further adversely affects companies that deal with these resources.

In such a complex situation, it is very important to identify all the changes that have occurred due to the COVID-19 pandemic so that managers can work to address them, with the goal that companies successfully overcome the current situation and continue to develop and work in the future.

This paper analyzes selected companies dealing with non-renewable natural resources in order to define the impact of the COVID-19 pandemic on their business in the new conditions. The analysis is based on the ranking of the most important consequences of the COVID-19 pandemic and the analysis of the obtained results.

\section{WORK METHODOLOGY}

The methodology of the work is defined with the aim of obtaining relevant results of the impact of the COVID-19 pandemic on the use of non-renewable natural resources. The methodology of the work is defined of sides the author and it is unique. Figure 1 shows the scheme of work methodologies.

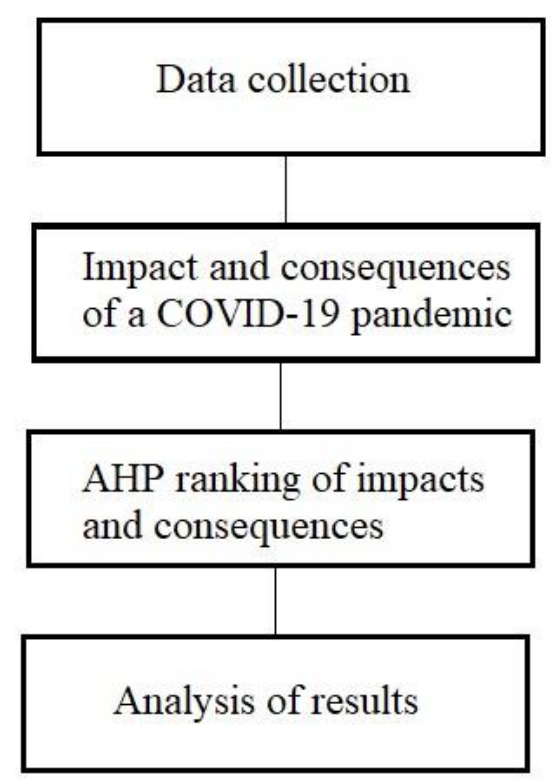

Figure 1 Schematic representation of the work methodology 
Figure 1 shows that research begins with collecting data on the impact and consequences of the COVID-19 pandemic on the use of non-renewable resources. This was done through interviews with managers of relevant companies. The questions are designed in such a way as to obtain the necessary data on the given impacts on the functioning of companies. After that, the authors, together with the managers of the companies, defined the final list of impacts and consequences. Based on that, the ranking of the given impacts and consequences was performed using the AHP method, where the assessments were given by the group decision-making method (authors and managers of mining companies).

After obtaining the ranking results, an analysis of the obtained results was performed, which has the task of pointing out the most important impacts and consequences of the COVID-19 pandemic on the use of non-renewable natural resources.

The aim of the analysis is to help the managers of the given companies to better understand the consequences and changes caused by the pandemic and, based on that, to adjust the business and functioning of their companies in order to survive in the given conditions, as well as to recover more easily after the pandemic.

\section{AHP METHOD}

AHP is a quantitative method that presents a complex decision problem using a multidimensional hierarchical structure of goals, criteria, and alternatives. AHP calculates the strength of the impact of each criterion, compares alternatives to each criterion, and performs a ranking of alternatives (Saaty, 1980).

Determining the relative impact of each criterion, as well as comparing alternatives to each criterion is done using a comparison matrix. Appropriate estimates are used to calculate the weights for each criterion, as well as all alternatives and degrees of consistency. The degree of consistency must be less than $10 \%(0,1)$. Comparison and calculation are performed on the basis of a scale with grades from 1 to 9 - Table 1 .

Table 1 Scale of comparison of decision elements

\begin{tabular}{lc}
\hline Dominance & Grade \\
\hline Description & 1 \\
\hline Equally & 3 \\
Weak dominance & 5 \\
Strong domination & 7 \\
Very strong dominance & 9 \\
Absolute domination & \\
\hline $2,4,6,8$ are intermediate values & \\
\hline
\end{tabular}

Determining the final rank of alternatives is done by synthesizing the results obtained at all levels. 
Bogdanović D., Miletić S.

\section{RANKING RESULT}

\subsection{Data collection}

As mentioned, the research is based on the results of interviews with company managers. On that occasion, the managers pointed out the impacts and consequences caused by the COVID-19 virus pandemic, as well as the way in which the companies function best in the given conditions. Based on that, a list of the most pronounced influences was obtained, as well as the biggest consequences.

\subsection{Impacts and consequences of the COVID-19 pandemic}

When the initial list of all listed impacts and consequences was obtained, their analysis was performed and a final list containing essential impacts and consequences was generated.

The list is as follows:

- Falling demand for fossil fuels (A1). The drop in demand is a consequence of the decline in economic activity during the COVID-19 pandemic. The drop in demand inevitably caused higher stocks and, as a consequence, a drop in fossil fuel production.

- Decline in fossil fuel supply (A2). The COVID-19 pandemic disrupted supply chains in almost all areas of the economy. This also happened with fossil fuels, which caused difficulties in the supply and distribution of this energy source.

- Falling fossil fuel prices (A3). The drop in demand inevitably led to a drop in the price of fossil fuels, which led to financial difficulties for many companies. Due to the pandemic, this drop in prices did not lead to an increase in the demand for fossil fuels.

- Decline in the price of most metals (A4). Everything that has been said about fossil fuels also applies to most metals. Increased inventories, reduced demand, problems in supply chains, all this has led to falling prices for most metals.

- Rising gold prices (A5). Gold in most crisis is gaining in importance, so that in a pandemic Covide-19 there was an increase in its price. Investors in crisis situations invest in gold because it gives them the greatest security opportunity to return the invested funds.

- High energy uncertainty (A6). The COVID-19 pandemic has caused great uncertainty in many areas, as well as in the field of energy. Uncertainty about the duration of the crisis, the disturbances that have occurred, as well as other negative consequences lead to general uncertainty regarding energy. 
- Decline in business volume and company profitability (A7). All the above consequences of the COVID-19 pandemic in the field of non-renewable natural resources have led to companies operating in this sector having major problems. These problems consist of the existence of large stocks of products, reduced production, falling demand and reduced revenue. As a result, many companies have found themselves in a difficult situation.

\subsection{AHP ranking impact and consequences}

After defining all the impacts and consequences in the conditions of the COVID-19 pandemic, they are ranked. The aim of the ranking is to get a result that identifies the most influential impact of a pandemic COVID-19 on non-renewable natural resources and therefore help managers in this industry that the best way to overcome the consequences problem date. The ranking of the impact and consequences of the COVID19 pandemic on non-renewable natural resources was performed by company managers and the authors of this paper. Table 2 shows the estimates shown in Table 1 when comparing the mutual influences and consequences COVID-19 in the non-renewable natural resources.

Table 2 Evaluation comparisons of optimization measures

\begin{tabular}{cccccccc}
\hline & A1 & A2 & A3 & A4 & A5 & A6 & A7 \\
\hline A1 & 1 & 3 & $1 / 4$ & 1 & $1 / 3$ & $1 / 5$ & $1 / 7$ \\
A2 & & 1 & $1 / 3$ & $1 / 3$ & $1 / 5$ & $1 / 5$ & $1 / 6$ \\
A3 & & & 1 & 1 & $1 / 3$ & $1 / 2$ & $1 / 7$ \\
A4 & & & & 1 & $1 / 3$ & $1 / 3$ & $1 / 5$ \\
A5 & & & & 1 & 1 & 1 \\
A6 & & & & & & 1 & $1 / 2$ \\
A7 & & & & & & & 1 \\
\hline
\end{tabular}

After that, with the help of Super Decisions software, the result of ranking the impact and consequences of COVID-19 on non-renewable natural resources was obtained.

First, the multidimensional hierarchical structure of impacts and consequences of COVID-19 on non-renewable natural resources was defined - Figure 2, and then the weight coefficients of the mentioned impacts and consequences of COVID-19 were determined (results are shown in Figure 3). 
Super Decisions Main Window: Primer_selection1.sdmod: formulaic: ratings

File Design Assess/Compare Computations Networks Help

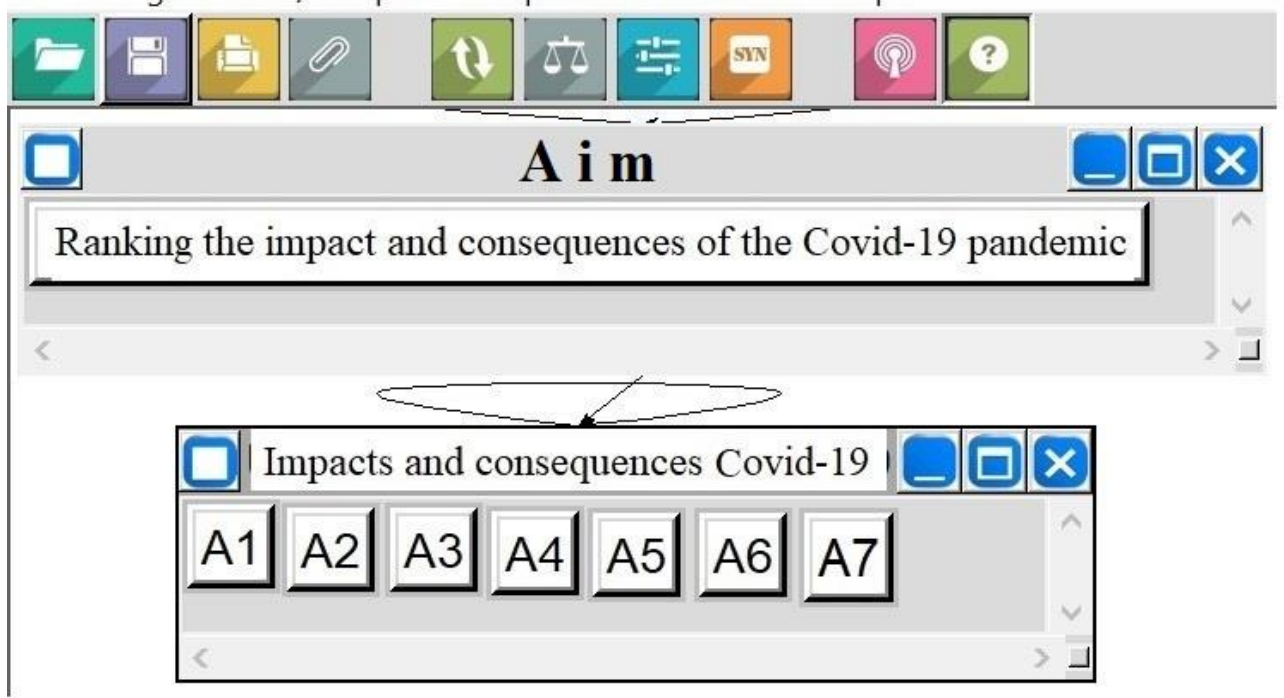

Figure 2 Multidimensional hierarchical structures of goals and measures

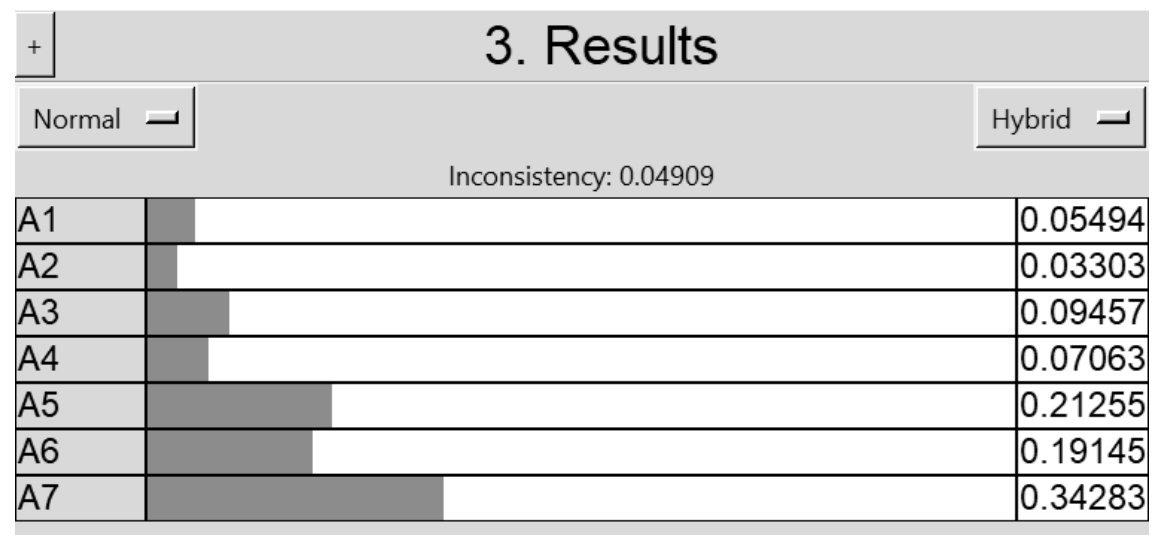

Figure 3 Ranking results

The degree of inconsistency is 0.04909 , which is less than 0.1 , so the results are reliable

\subsection{Analysis of results}

The obtained results (Table 3) show the significance and magnitude of the impact, as well as the consequences of the COVID-19 pandemic on the use of non-renewable natural resources. 
Table 3 Ranking result with weighting coefficients

\begin{tabular}{clc}
\hline Row. no & Proposed measures & Result \\
\hline 1. & A7 (Decline in business volume and profitability of & 0,34283 \\
& companies) & 0,21255 \\
2. & A5 (Rising gold prices) & 0,19145 \\
3. & A6 (High energy uncertainty) & 0,09457 \\
.. & A3 (Fall in prices of fossil fuels) & 0,07063 \\
5. & A4 (Decline in the price of most metals) & 0,05494 \\
6. & A1 (Decline in demand for fossil fuels) & 0,03303 \\
7. & A2 (Decline in fossil fuel supply) \\
\hline
\end{tabular}

The results show that the impacts and consequences of the COVID-19 pandemic can be divided into three groups in terms of the magnitude of their impact on the use of nonrenewable natural resources.

The first group includes the consequence of the decline in business volume and profitability of companies (A7). The decline in the volume of business and profitability of companies is, according to managers, the most severe consequence of the pandemic because it endangers the survival, work and development of companies. Without strong companies, the use of non-renewable resources is significantly reduced, which has negative consequences for other economic activities and society as a whole. On the other hand, companies have difficulty operating, making smaller profits and some losses, and this significantly slows down the growth of this industry.

The second group includes the impacts and consequences of A5 (rising gold prices) and A6 (high energy uncertainty). The rise in the price of gold is always present in difficult and crisis situations, because investors believe that they will best protect and secure their capital if they invest in gold. Therefore, as the second most significant consequence of the COVID-19 pandemic, there is an increase in the price of gold because there is a great demand for it. Also, in the third place is the consequence of great energy insecurity. Namely, the COVID-19 pandemic has led to insecurity in all fields, but it is especially pronounced in the field of energy. Uncertainty occurs due to reduced consumption, reduced production, difficult situation of companies that produce energy, disruptions in supply chains, etc.

The third group includes the remaining impacts and consequences - A3 (fall in the price of fossil fuels), A4 (fall in the price of most metals), A1 (fall in demand for fossil fuels) and A2 (fall in the supply of fossil fuels). Increased inventories have caused prices for both fossil fuels and most metals to fall. Inventories arose due to reduced demand, but also due to disruptions in supply chains. The largest oscillations related to the fall in prices occur with fossil fuels (oil, gas), while they are smaller with metals. The decline in demand for fossil fuels is a consequence of declining economic activity during the pandemic. For example, the services and tourism sector are almost halted. On the other hand, the volume of traffic, movement of people, etc. has been reduced. Also, during the 
COVID-19 pandemic, there was a drop in the supply of fossil fuels. This is a consequence of problems in supply chains, but also a consequence of the reduction of production volume due to falling prices, etc.

\section{CONCLUSION}

The paper is applied AHP method for ranking the impact and consequences of the pandemic Covide-19 on the use of non-renewable natural resources. Seven types of impacts and consequences were considered - A1 (decrease in demand for fossil fuels), A2 (decrease in supply of fossil fuels), A3 (decrease in the price of fossil fuels), A4 (decrease in the price of most metals), A5 (increase in the price of gold), A6 high energy uncertainty) and A7 (decline in business volume and company profitability). Based on the results obtained by the AHP method, the most severe impacts and consequences on the use of non-renewable natural resources are A7 (decline in business volume and profitability of companies), A5 (increase in gold prices) and A6 (high energy uncertainty). The weakest consequence is A2 (decline in fossil fuel supply), although it had an impact on the economy and the population.

The results of ranking the impact and consequences of the COVID-19 pandemic on the use of non-renewable natural resources can be used to help managers of companies in this field of business in terms of easier identification of problems and, based on that, defining appropriate actions to overcome them.

\section{ACKNOWLEDGMENTS}

The research presented in this paper was done with the financial support of the Ministry of Education, Science and Technological Development of the Republic of Serbia, within the financing of scientific research work in the Institute of Mining and Metallurgy Bor, according to the Contract No. 451-03-9/2021-14/200052, and at the University of Belgrade, Technical Faculty in Bor, according to the Contract No. 451-03-9/2021$14 / 200131$.

\section{REFERENCES}

DELLOITE. (2020) Understanding COVID-19's Impact on the Mining \& Metals Sector. Guidance for Mining \& Metals Executives COVID19: Mining Industry Impact and Response. Available online: https://www.flsmidth.com/en-gb/discover/mining-2020 /mining-industry-impact-and-response.

GAŁAS', A. et al. (2021) Impact of Covid-19 on the Mining Sector and Raw Materials Security in Selected European Countries. Resources, 10(39)

HILSON, G. et al. (2021) Artisanal and small-scale mining, and COVID-19 in subSaharan Africa: A preliminary analysis. World Development, 139. 
LAING, T. (2020) The economic impact of the Coronavirus 2019 (Covid-2019): Implications for the mining industry. The Extractive Industries and Society, 7, pp. 580 582.

SAATY, T.L. (1980) The Analytical Hierarchy Process. McGraw-Hill, New York, USA. 